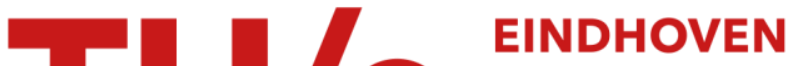 \\ UNIVERSITY OF \\ TECHNOLOGY
}

\section{Planar monomode optical couplers based on multimode interference effects}

\section{Citation for published version (APA):}

Soldano, L. B., Veerman, F. B., Smit, M. K., Verbeek, B. H., Dubost, A. H., \& Pennings, E. C. M. (1992). Planar monomode optical couplers based on multimode interference effects. Journal of Lightwave Technology, 10(12), 1843-1850.

Document status and date:

Published: 01/01/1992

\section{Document Version:}

Publisher's PDF, also known as Version of Record (includes final page, issue and volume numbers)

\section{Please check the document version of this publication:}

- A submitted manuscript is the version of the article upon submission and before peer-review. There can be important differences between the submitted version and the official published version of record. People interested in the research are advised to contact the author for the final version of the publication, or visit the $\mathrm{DOI}$ to the publisher's website.

- The final author version and the galley proof are versions of the publication after peer review.

- The final published version features the final layout of the paper including the volume, issue and page numbers.

Link to publication

\section{General rights}

Copyright and moral rights for the publications made accessible in the public portal are retained by the authors and/or other copyright owners and it is a condition of accessing publications that users recognise and abide by the legal requirements associated with these rights.

- Users may download and print one copy of any publication from the public portal for the purpose of private study or research.

- You may not further distribute the material or use it for any profit-making activity or commercial gain

- You may freely distribute the URL identifying the publication in the public portal.

If the publication is distributed under the terms of Article 25fa of the Dutch Copyright Act, indicated by the "Taverne" license above, please follow below link for the End User Agreement:

www.tue.nl/taverne

Take down policy

If you believe that this document breaches copyright please contact us at:

openaccess@tue.nl

providing details and we will investigate your claim. 


\section{Planar Monomode Optical Couplers Based on Multimode Interference Effects}

Lucas B. Soldano, Frank B. Veerman, Meint K. Smit, Bastiaan H. Verbeek, Alain H. Dubost, and Erik C. M. Pennings

\begin{abstract}
The self-imaging property of a homogeneous multimoded planar optical waveguide has been applied in the design of passive planar monomode optical couplers based on multimode interference (MMI). Based on these designs, $3 \mathrm{~dB}$ and cross couplers were fabricated in $\mathrm{SiO}_{2} / \mathrm{Al}_{2} \mathrm{O}_{3} / \mathrm{SiO}_{2}$ channel waveguides on Si substrates. Theoretical predictions and experimental results at $1.52-\mu \mathrm{m}$ wavelength are presented which demonstrate that MMI couplers offer high performance: on-chip excess loss better than $0.5 \mathrm{~dB}$, high reproducibility, low polarization dependence and small device size.
\end{abstract}

\section{INTRODUCTION}

O PTICAL couplers are key components in photonic integrated circuits both for signal routing and signal processing. Two-mode interference (TMI) couplers were already proposed in 1977 [1] as a simpler alternative to the weak synchronous couplers based on parallel waveguides, and reported in 1988 [2] to build integrated-optic dual-channel wavelengthdivision multi-/demultiplexers. TMI couplers consist of a twomoded central waveguide (TMI section) connected to two pairs of single-moded access waveguides (Fig. 1(a)). Compared to weak synchronous couplers, TMI couplers are shorter, less sensitive to fabrication variations and less polarization dependent. However, requirements of high power coupling efficiency and proper mode excitation from the single-moded access waveguides to the TMI section limit the branching angle of the access waveguides to very small values (typically $<2^{\circ}[3]$ ). Due to the finite resolution of the lithographic process, part of the area between the access waveguides (shaded regions in Fig. 1(a)) will become filled in a nonreproducible way. This introduces considerable uncertainty in the actual length of the TMI section, causing spread in coupler performance. Moreover, due to the proximity of the access waveguides, extra modal coupling occurs [4], adding to the performance spread.

We show that replacing the TMI section by a (wider) multimode interference (MMI) section while keeping singlemoded access waveguides (Fig. 1(b)) allows a good separation of the access waveguides, eliminating the performance spread due to both the filling-in and the extra coupling in the access

Manuscript received January 20,1992; revised July 30, 1992. This work was supported in part by the Netherlands Technology Foundation (STW) as part of the program of the Foundation for Fundamental Research on Matter (FOM), and the IOP-Electro Optics program.

L. B. Soldano, F. B. Veerman, M. K. Smit, and B. H. Verbeck are with the Department of Electrical Engineering, Laboratory of Telecommunication and Remote Sensing Technology, Delft University of Technology, 2600 GA Delft, The Netherlands.

A.H. Dubost is with the Département Communications, Ecole Nationale Supérieure des Télécommunications, 75634 Paris, France.

E. C. M. Pennings is with Bellcore, Red Bank, NJ 07701-7040 IEEE Log Number 9204436.

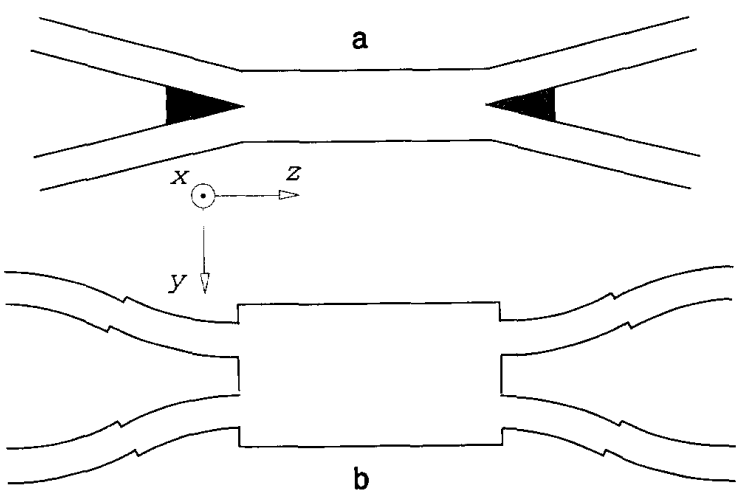

Fig. 1. (a) Classical two mode interference (TMI) coupler showing the filled-in areas. (b) Multimode interference (MMI) coupler. The center section supports a high number of modes while the access waveguides are single moded.

waveguides. Furthermore, due to the high number of modes supported by the MMI section, power coupling efficiencies are higher and consequently device excess losses are lower compared to those of TMI couplers (which can reach up to $3 \mathrm{~dB}[3])$.

Experimental results on MMI couplers were recently reported by us [5]-[7]. This paper provides the theoretical background of the self-imaging effect in multimoded waveguides, a detailed verification of the restricted multimode selfimaging effect, design considerations for the MMI couplers, simulation predicted performances and measurement results of the integrated devices.

\section{Self-Imaging in Multimoded Waveguides}

\section{A. General Multimode Resonances}

The operation of the MMI coupler is based on the selfimaging property of a multimoded waveguide, as suggested by Bryngdahl [8] and described in more detail by Ulrich [9], [10]. The propagation constants $\beta_{0 v}$ of the modes supported by a multimoded waveguide (MMI section) with slab effective index of refraction $N_{I}$ and width $W_{M M I}$ (Fig. 2) show a nearly quadratic dependence with the lateral mode number $\nu$ :

$$
\beta_{0 v} \simeq \sqrt{k_{0}^{2} N_{I}^{2}-\frac{\pi^{2}(\nu+1)^{2}}{W_{\mathrm{MMI}}^{2}}} \simeq k_{0} N_{I}-\frac{\pi^{2}(\nu+1)^{2}}{2 k_{0} N_{I} W_{\mathrm{MMI}}^{2}}
$$

which follows from $k_{y}^{2}+k_{z}^{2}=k_{0}^{2} N_{I}^{2}$ with $k_{z}=\beta_{0 \nu}$, $k_{y} \approx(\nu+1) \pi / W_{\mathrm{MMI}}$ and the fact that $\beta_{0 \nu}$ is close to $k_{0} N_{I}$. 


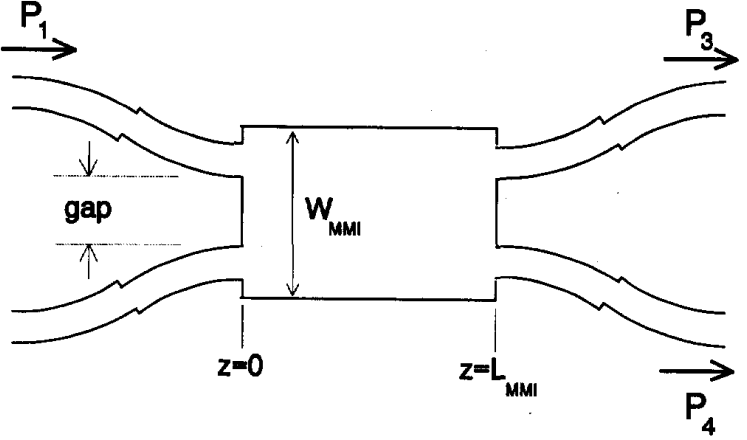

Fig. 2. Schematic structure of the multimode interference coupler, with dimensions and definitions. Offsets were applied at the transitions of the curved access waveguides to minimize losses.

Defining the beat length $L_{\pi} \triangleq \pi /\left(\beta_{00}-\beta_{01}\right)$, the propagation constants of the modes in the MMI section become

$$
\beta_{0 \nu} \simeq k_{0} N_{I}-\frac{\pi(\nu+1)^{2}}{3 L_{\pi}}
$$

The total lateral field profile $h_{x}(y, z)$ at any $z$ position in the MMI section can be written as a linear combination of the fields $h_{x, \nu}(y)$ of the $M$ guided modes:

$$
h_{x}(y, z)=\sum_{\nu=0}^{M-1} c_{\nu} h_{x, \nu}(y) \exp \left(-j \beta_{0 \nu} z\right)
$$

where the coefficients $c_{\nu}$ determine the relative contribution of each mode. In particular, the total lateral field profile at the entrance $(z=0)$ of the MMI section is

$$
h_{x}(y, 0)=\sum_{\nu=0}^{M-1} c_{\nu} h_{x, \nu}(y)
$$

which reflects the decomposition of the input field profile into all guided modes. The coefficients of this decomposition can be found with the overlap integral performed between the input field profile $h_{x}(y, 0)$ and each guided mode $h_{x, \nu}(y)$ :

$$
c_{\nu}^{2}=\frac{\left|\int h_{x}(y, 0) h_{x, \nu}^{*}(y) d y\right|}{\sqrt{\int\left|h_{x}(y, 0)\right|^{2} d y \int\left|h_{x, \nu}(y)\right|^{2} d y}}
$$

And, using the propagation constants given by (2), the total lateral field profile at the end ( $\left.z=L_{\mathrm{MMI}}\right)$ of the MMI section can be found from (3):

$$
\begin{aligned}
h_{x}\left(y, L_{\mathrm{MMI}}\right)= & \exp \left[-j k_{0} N_{I} L_{\mathrm{MMI}}\right] \sum_{\nu=0}^{M-1} c_{\nu} h_{x, \nu}(y) \\
& \cdot \exp \left[j \frac{\pi(\nu+1)^{2} L_{\mathrm{MMI}}}{3 L_{\pi}}\right] .
\end{aligned}
$$

Inspection of the phase factor leads to the example as it appears in (7) at bottom of page where $q$ is an integer number and the overall phase factor $\exp \left[-j k_{0} N_{I} L_{M M I}\right]$ has been dropped. The even and odd symmetry of the modes can be used to rewrite the previous results in terms of the total lateral field profile at the input $h_{x}(y, 0)$, see (8) at bottom of page.These results show that:

a. When $L_{\mathrm{MMI}}=2 q\left(3 L_{\pi}\right)$, the field at the entrance is reproduced at the end of the MMI section (self-imaging effect), and the coupler is in the bar state.

b. When $L_{\mathrm{MMI}}=(2 q+1)\left(3 L_{\pi}\right)$, the field at the end of the MMI section is an $x z$-plane mirror image of the field at the entrance, and the coupler is in the cross state.

c. When $L_{\mathrm{MMI}}=(2 q+1 / 2)\left(3 L_{\pi}\right)$, the field at the end of the MMI section is a linear combination of the original field at the entrance and its $x z$-plane mirror image with a relative phase of $\pi / 2$, which means that the coupler operates in the $3-\mathrm{dB}$ state.

Similarly, it can be proven (see Appendix A) that if the modes $2,5,8, \cdots$ in the MMI section are not excited, i.e., if

$$
c_{\nu}=0 \quad \text { for } \nu=2,5,8, \cdots
$$

then similar resonances as stated by (7) occur for MMI section

$$
h_{x}\left(y, L_{\mathrm{MMI}}\right)=\left\{\begin{array}{l}
\sum c_{\nu} h_{x, \nu}(y) \\
\sum(-1)^{\nu+1} c_{\nu} h_{x, \nu}(y) \\
\sum_{\nu \text { even }} j(-1)^{q} c_{\nu} h_{x, \nu}(y)+\sum_{\nu \text { odd }} c_{\nu} h_{x, \nu}(y)
\end{array} \quad \text { for } L_{\mathrm{MMI}}=\left\{\begin{array}{c}
(2 q)\left(3 L_{\pi}\right) \\
(2 q+1)\left(3 L_{\pi}\right) \\
\left(q+\frac{1}{2}\right)\left(3 L_{\pi}\right)
\end{array}\right.\right.
$$

$$
h_{x}\left(y, L_{\mathrm{MMI}}\right)=\left\{\begin{array}{l}
h_{x}(y, 0) \\
-h_{x}(-y, 0) \\
\frac{j(-1)^{q}+1}{2} h_{x}(y, 0)+\frac{j(-1)^{q}-1}{2} h_{x}(-y, 0)
\end{array} \quad \text { for } L_{\mathrm{MMI}}=\left\{\begin{array}{c}
(2 q)\left(3 L_{\pi}\right) \\
(2 q+1)\left(3 L_{\pi}\right) . \\
\left(q+\frac{1}{2}\right)\left(3 L_{\pi}\right)
\end{array}\right.\right.
$$




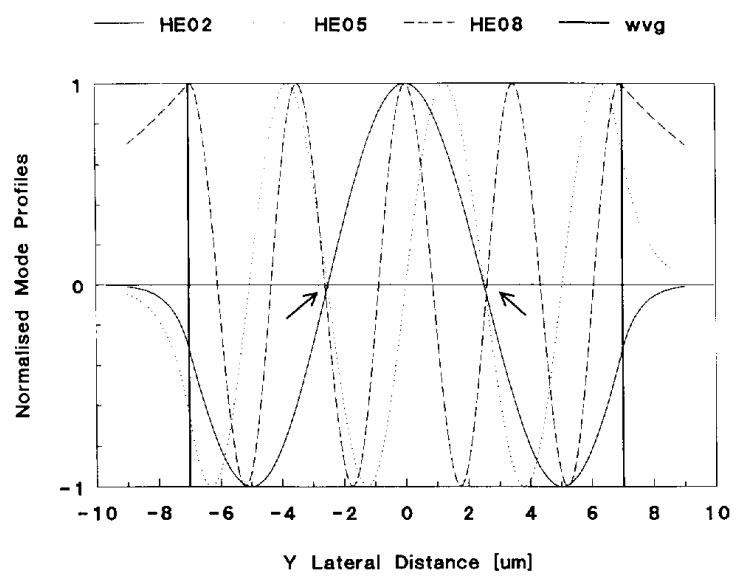

Fig. 3. The normalized lateral field profiles of the $2^{\text {nd }}, 5^{\text {th }}$, and $8^{\text {th }}$ order modes in the $14-\mu \mathrm{m}$ wide MMI section. All these modes present a zero and odd symmetry around the same $y$-position $(y \approx \pm 2.55 \mu \mathrm{m}$, marked by arrows).

lengths which are multiple of $L_{\pi}$ instead of $3 L_{\pi}$, thus allowing the design of couplers with MMI sections three times shorter. We call this phenomenon restricted multimode resonances.

\section{B. Discussion}

It was shown that the multimode resonances can be achieved either at MMI section lengths which are multiple of $3 L_{\pi}$ (general multimode resonances), or MMI section lengths which are multiple of $L_{\pi}$ (restricted multimode resonances). The general multimode resonance mechanism holds irrespective of the input field profile $h_{x}(y, 0)$, but demands a rather long device. The restricted resonance mechanism, on the other hand, offers the possibility of much shorter devices at the cost of complying with the selective excitation stated in (9). This selective excitation, however, can be readily achieved through a correct shaping and positioning of the input field profile $h_{x}(y, 0)$. The field profiles of the $2^{\text {nd }}, 5^{\text {th }}, 8^{\text {th }}, \cdots$ order modes, shown in Fig. 3 for a nine-moded waveguide, present zeros (and odd symmetry) at almost the same $y$ positions (about $1 / 3$ and $2 / 3$ of $W_{\mathrm{MMI}}$ ). Therefore, providing a fundamental (even symmetric) mode as input field profile $h_{x}(y, 0)$ and centering it around the simultaneous zeros ensures very low excitation of those modes. We pursued this strategy for the design and realization of two sets of MMI couplers working in the 3-dB state and cross state.

\section{Modeling of the MMI Couplers}

Rib-type waveguides have been analyzed with the effectiveindex method [11]. The overlap integral (5) is applied at the entrance of the MMI section to evaluate all excitation coefficients. Fig. 4 shows the power excitation coefficients $c_{\nu}^{2}$, calculated with the overlap integral between a fundamental mode input profile and the $2^{\text {nd }}, 5^{\text {th }}$, and $8^{\text {th }}$ order modes in the MMI section as a function of the $y$ offset, i.e., the lateral distance between the center of the MMI section and the peak of the fundamental mode profile in the access waveguide. This

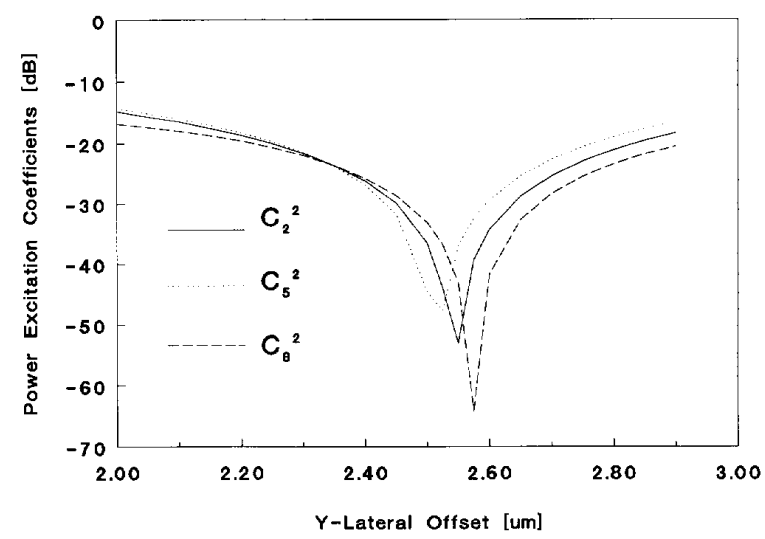

Fig. 4. Power excitation coefficients calculated with the overlap integral between a fundamental mode input profile and the $2^{\text {nd }}, 5^{\text {th }}$, and $8^{\text {th }}$ order modes in the $14-\mu \mathrm{m}$-wide MMI section.

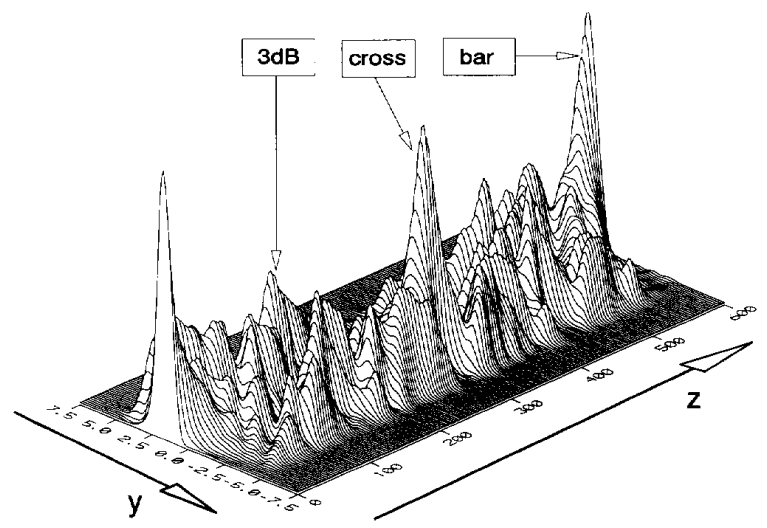

Fig. 5. Intensity distribution in the MMI section. The launched mode profile can be seen at $z=0$. The labels indicate the $3-\mathrm{dB}$ state, the cross state and the bar state.

plot allows the choice of the optimum gap (as defined in Fig. 2) to best satisfy the selective excitation of (9). In our case, a $2.55-\mu \mathrm{m} y$ offset was adopted, which results in $c_{2}^{2}=-53 \mathrm{~dB}$, $c_{5}^{2}=-37 \mathrm{~dB}, c_{8}^{2}=-43 \mathrm{~dB}$ and a gap of

$$
\text { gap }=2 \mathrm{off}-w+2 \delta=3.30 \mu \mathrm{m}
$$

where off is the $y$ offset, $w$ is the width of the curved access waveguides and $\delta$ is the lateral displacement of the peak of the fundamental mode toward the outer ridge due to the curvature of the access waveguides (in our case $w=2 \mu \mathrm{m}$, $\delta \approx 0.1 \mu \mathrm{m})$.

With these data, a mode-propagation calculation (3) is used to obtain the total field at any $z$ position in the MMI section. Fig. 5 shows the total intensity distribution within the MMI section, calculated in this way. Finally, an overlap integral between the field at the end of the MMI section and the field in the single-moded output waveguides allows to predict the optical power in each output branch.

With the procedure just described, sensitivity analysis can be performed of the behavior of the couplers to some fabrication 


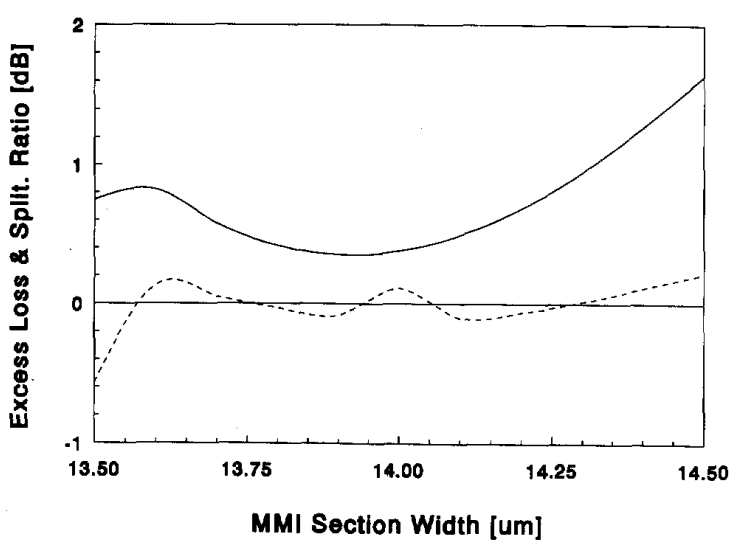

Fig. 6. Sensitivity analysis of the excess loss (solid line) and splitting ratio (dashed line) to the MMI section width for the 3-dB couplers.

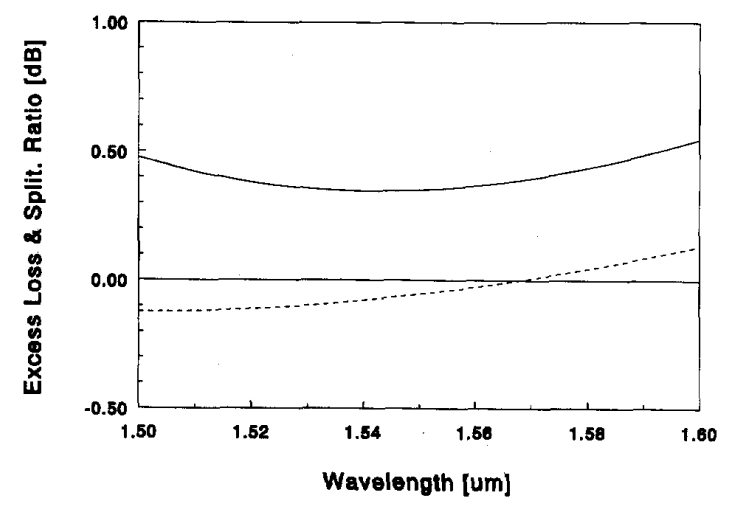

Fig. 7. Sensitivity analysis of the excess loss (solid line) and splitting ratio (dashed line) to the wavelength for the $3-\mathrm{dB}$ couplers.

parameters (e.g., the MMI section width, the MMI section length, etc.) or operation parameters (e.g., the wavelength $\lambda$, the state of polarization, etc.). For the $3-d B$ couplers two figures of merit are defined (refer to Fig. 2): Excess Loss $=10$ $\log \left(\left(P_{3}+P_{4}\right) / P_{1}\right)$, and Splitting Ratio $=10 \log \left(P_{3} / P_{4}\right)$. For the cross couplers: Insertion Loss $=10 \log \left(P_{4} / P_{1}\right)$, and Cross Talk $=10 \log \left(P_{3} / P_{4}\right)$. Fig. 6 shows the sensitivity of the 3$\mathrm{dB}$ couplers to variations in the width of the MMI section. It can be seen that in order to obtain excess losses lower than $1 \mathrm{~dB}$ and splitting ratios better than $0.1 \mathrm{~dB}, W_{\mathrm{MMI}}$ must be within $\pm 0.40 \mu \mathrm{m}$ from its optimum value. Fig. 7 shows the sensitivity of the 3-dB couplers to variations in the wavelength. For a wavelength range between 1.52 and $1.59 \mu \mathrm{m}$ the excess loss is better than $0.5 \mathrm{~dB}$ and the splitting ratio remains within $0.1 \mathrm{~dB}$.

\section{FABrication of the DeVICES}

The devices were implemented in the dielectric rib-type waveguide structure shown in Fig. 8. A 0.6- $\mu \mathrm{m} \mathrm{Al}_{2} \mathrm{O}_{3}$ guiding film is r.f. sputtered onto a $5-\mu \mathrm{m} \mathrm{SiO}_{2}$ cladding layer thermally grown on a (110) Si substrate. The channel waveguides are shaped by a $0.3-\mu \mathrm{m}$ Argon-beam etching after being defined by photolithography. A $1.35-\mu \mathrm{m}$ sputtered $\mathrm{SiO}_{2}$ provides a

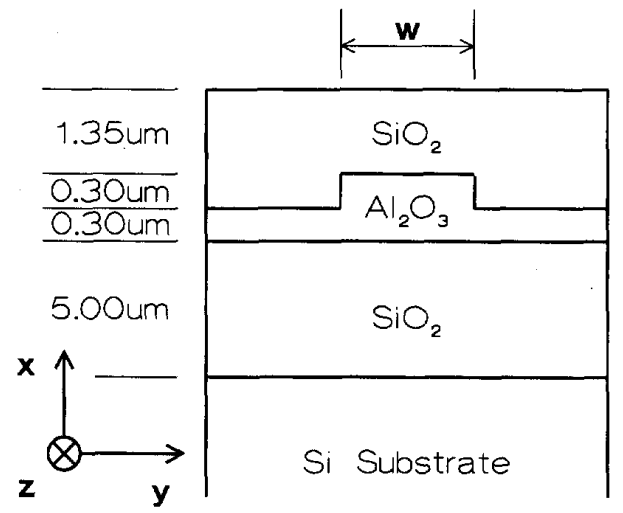

Fig. 8. Cross-section view of the $\mathrm{SiO}_{2} / \mathrm{Al}_{2} \mathrm{O}_{3} / \mathrm{SiO}_{2}$ dielectric rib-type waveguide structure on $\mathrm{Si}$ substrate.

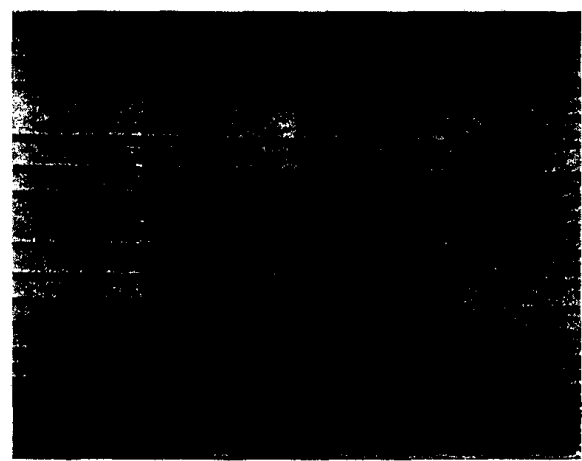

Fig. 9. Nomarsky photograph of the realized 3-dB MMI couplers. The identification numbers on the left indicate the MMI section length in micrometers.

top cover layer. A final thermal annealing step resulted in optical waveguide attenuations of $1 \mathrm{~dB} / \mathrm{cm}$ at $0.6328 \mu \mathrm{m}$ and $0.3 \mathrm{~dB} / \mathrm{cm}$ at $1.55 \mu \mathrm{m}[12]$.

Two sets of devices (3-dB and cross couplers) were designed and fabricated for operation at $1.52-\mu \mathrm{m}$ wavelength. The set of 3-dB couplers has $W_{\mathrm{MMI}}=14 \mu \mathrm{m}$ (supporting a total of 9 modes). The simulated optimum length for the MMI section is only $155 \mu \mathrm{m}$. Couplers were fabricated with $L_{\mathrm{MMI}}$ ranging from 120 to $190 \mu \mathrm{m}$ in steps of $5 \mu \mathrm{m}$.

The set of cross couplers has $W_{\mathrm{MMI}}=12 \mu \mathrm{m}$ (supporting a total of 7 modes). The simulated optimum length for the MMI section is $236 \mu \mathrm{m}$. Couplers were fabricated with $L_{\mathrm{MMI}}$ ranging from 200 to $270 \mu \mathrm{m}$ in steps of $5 \mu \mathrm{m}$.

Fig. 9 shows a microscope photograph of the realized couplers. Straight access waveguides are $2-\mu \mathrm{m}$ wide, and curved access waveguides have $300-\mu \mathrm{m}$ radii, a width of $2 \mu \mathrm{m}$, are strictly single-moded and provide a lateral access waveguide separation of $30 \mu \mathrm{m}$. Reference channel waveguides are included running alongside each device, which allow monitoring of the input launched optical intensity.

\section{EXPERIMENTAL RESULTS}

Measurements were carried out by coupling a $1.52-\mu \mathrm{m}$ wavelength FP laser beam by means of a prism-coupling 


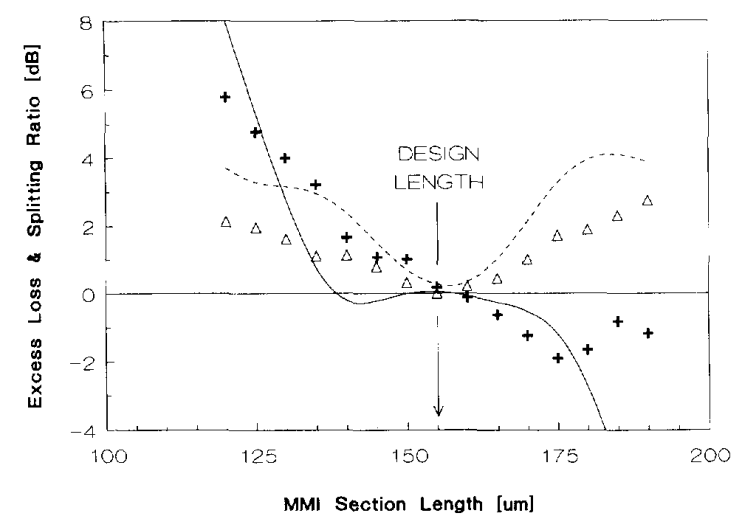

Fig. 10. Excess loss and splitting ratio of the $3-\mathrm{dB}$ couplers. Solid line is simulated and $(+)$ markers are measured splitting ratio values. Dashed line is simulated and $(\Delta)$ markers are measured excess loss values.

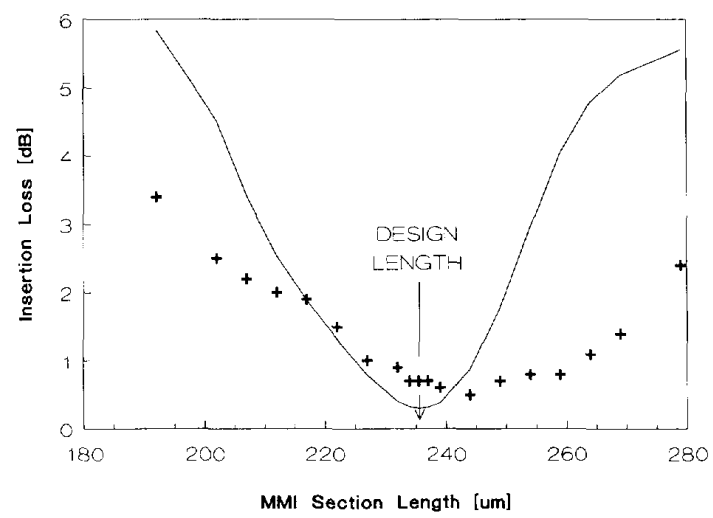

Fig. 11. Insertion loss of the cross couplers. Solid line is simulated and $(+)$ markers are measured insertion loss values.

technique [13] to one of the input access waveguides ( $P_{1}$ in Fig. 2) and recording the light intensities at both output access waveguides ( $P_{3}$ and $P_{4}$ in Fig. 2) from the polished end-face. Each coupler was repeated three times in the layout and each layout was repeated three times in the silicon wafer in order to test in-wafer repeatability.

Experimental data is shown in Figs. 10 and 11. Lines represent computer-simulated results and markers are measured values, each being an average from nine nominally identical devices.

Fig. 10 presents the results for the $3-\mathrm{dB}$ couplers. The measured splitting ratio for the optimum designed MMI section length is below $0.2 \mathrm{~dB}$ and simultaneously the excess loss reaches a minimum (measured to be around $0.2 \mathrm{~dB}$ ).

Fig. 11 presents the results for the cross couplers. The measured insertion loss for the optimum designed MMI section length is $0.8 \mathrm{~dB}$ and the measured cross talk is $-18 \mathrm{~dB}$, reaching $0.5-\mathrm{dB}$ insertion loss and the same cross talk figure for a slightly larger MMI section length.

The design of the couplers was optimized for TEpolarization. When tested for TM-polarization they showed an average of $0.2 \mathrm{~dB}$ extra excess/insertion loss but no appreciable deterioration in the splitting ratio figure.
Measurements agree quite well with computer simulations in the region around the optimum designed MMI section length. We attribute the discrepancy in the adjacent regions to a lower number of modes being guided in the MMI section, due to an obtained ridge profile somewhat smoother than the one depicted in Fig. 8.

\section{CONCLUSIONS}

A mathematical description of the self-imaging property (both for the general and restricted resonance cases) in multimoded waveguides has been given and was applied to the design of passive integrated $2 \times 2$ optical couplers. Simulations were carried out which indicated high performance and low sensitivity to fabrication and operation parameters. Cross couplers and 3-dB couplers were fabricated in a channel dielectric waveguide structure and tested at $1.52-\mu \mathrm{m}$ wavelength.

Experimental agreement with computer-simulated behavior is very good. All measured quantities show rather flat curves with respect to the MMI section length, providing an indication of the good tolerance to this process parameter. The most critical parameter in the fabrication of the couplers is the MMI section width, which should be controlled to $\pm 0.40 \mu \mathrm{m}$ from its nominal value in order to achieve acceptable excess loss and splitting ratio figures.

Due to its good tolerance to process and operation parameters, this new coupler is suitable for making part of more complex OEIC's such as phase diversity networks [14] and electrooptic waveguide switches [15]. The self-imaging property opens the way to interesting perspectives for the realization of very compact $N \times N$ optical hybrids, which are currently under study.

\section{APPENDIX A}

\section{A. The Restricted Multimode Resonances}

It will be verified here that the same resonances as stated by (7) also occur for MMI section lengths which are multiple of $L_{\pi}$ instead of $3 L_{\pi}$ provided that (9) is fulfilled. We start therefore by expressing the condition in (9) using modulo- $m$ operation:

$$
c_{\nu}=0 \quad \text { for } \bmod _{3}[\nu]=2
$$

From (6), the lateral field at the end of the MMI section can then be explicitly written as:

$$
\begin{aligned}
h_{x}\left(y, L_{\mathrm{MMI}}\right)=\sum_{p=0}^{S}[ & c_{3 p} h_{x, 3 p}(y) \exp \left(j \pi \frac{(3 p+1)^{2} L_{\mathrm{MMI}}}{3 L_{\pi}}\right) \\
& +c_{3 p+1} h_{x, 3 p+1}(y) \\
& \left.\cdot \exp \left(j \pi \frac{(3 p+2)^{2} L_{\mathrm{MMI}}}{3 L_{\pi}}\right)\right]
\end{aligned}
$$

were the top summation limit $S$ is chosen as $S=\operatorname{int}(M / 3)$. 
The first term accounts for modes $v=3 p$, and the second term accounts for modes $v=3 p+1$ in the MMI section, with $p=0,1,2, \cdots$. For $L_{\mathrm{MMI}}=(2 q) L_{\pi}$, substitution into (A2) gives:

$$
\begin{aligned}
& h_{x}\left(y, L_{\mathrm{MMI}}\right)=\sum_{p=0}^{S}\left[c_{3 p} h_{x, 3 p}(y) \exp \left(j 2 q \pi \frac{(3 p+1)^{2}}{3}\right)\right. \\
& +c_{3 p+1} h_{x, 3 p+1}(y) \\
& \left.\cdot \exp \left(j 2 q \pi \frac{(3 p+2)^{2}}{3}\right)\right] \text {. }
\end{aligned}
$$

By noting that

$$
\left\langle\begin{array}{l}
\bmod _{3}\left[(3 p+1)^{2}\right]=1 \\
\bmod _{3}\left[(3 p+2)^{2}\right]=1
\end{array} \quad \text { for all } p\right.
$$

equation (A3) can be simplified by factorizing $\exp (j 2 q \pi / 3)$

$$
\begin{aligned}
h_{x}\left(y, L_{\mathrm{MMI}}\right)= & \exp \left(j 2 q \frac{\pi}{3}\right) \\
& \cdot \sum_{p=0}^{S}\left[c_{3 p} h_{x, 3 p}(y)\right. \\
& \left.+c_{3 p+1} h_{x, 3 p+1}(y)\right] .
\end{aligned}
$$

Comparing with (A2) we see that the field at the end of the MMI section reproduces the field at the entrance, which means that the coupler is in the bar state. For $L_{\mathrm{MMI}}=(2 q+1) L_{\pi}$, substitution into (A2) now gives

$$
\begin{aligned}
h_{x}\left(y, L_{\mathrm{MMI}}\right)=\sum_{p=0}^{S}[ & c_{3 p} h_{x, 3 p}(y) \\
& \cdot \exp \left(j(2 q+1) 2 \pi \frac{(3 p+1)^{2}}{6}\right) \\
& +c_{3 p+1} h_{x, 3 p+1}(y) \\
& \left.\cdot \exp \left(j(2 q+1) 2 \pi \frac{(3 p+2)^{2}}{6}\right)\right] .
\end{aligned}
$$

By noting that

$$
\begin{aligned}
& \left\langle\begin{array}{l}
\bmod _{6}\left[(3 p+1)^{2}\right]=1 \\
\bmod _{6}\left[(3 p+2)^{2}\right]=4
\end{array} \text { for } p\right. \text { even } \\
& \left\langle\begin{array}{l}
\bmod _{6}\left[(3 p+1)^{2}\right]=4 \\
\bmod _{6}\left[(3 p+2)^{2}\right]=1
\end{array} \quad \text { for } p\right. \text { odd }
\end{aligned}
$$

the field at the end of the MMI section is

$$
\begin{aligned}
h_{x}\left(y, L_{\mathrm{MMI}}\right)=\sum_{p \text { even }}[ & c_{3 p} h_{x, 3 p}(y) \exp \left(j(2 q+1) \frac{\pi}{3}\right) \\
& +c_{3 p+1} h_{x, 3 p+1}(y) \\
& \left.\cdot \exp \left(j(2 q+1) \frac{4 \pi}{3}\right)\right]
\end{aligned}
$$

$$
\begin{aligned}
+\sum_{p \text { odd }}[ & c_{3 p} h_{x, 3 p}(y) \exp \left(j(2 q+1) \frac{4 \pi}{3}\right) \\
& +c_{3 p+1} h_{x, 3 p+1}(y) \\
& \left.\cdot \exp \left(j(2 q+1) \frac{\pi}{3}\right)\right]
\end{aligned}
$$

Now, $\nu=3 p$ represents the even modes for $p$ even and the odd modes for $p$ odd, whereas $\nu=3 p+1$ represents the odd modes for $p$ even and the even modes for $p$ odd. Thus:

$$
\begin{aligned}
h_{x}\left(y, L_{\mathrm{MMI}}\right)= & \sum_{\nu \text { even }} c_{\nu} h_{x, \nu}(y) \exp \left(j(2 q+1) \frac{\pi}{3}\right) \\
& +\sum_{\nu \text { odd }} c_{\nu} h_{x, \nu}(y) \\
& \cdot \exp \left(j(2 q+1) \frac{4 \pi}{3}\right) \\
h_{x}\left(y, L_{\mathrm{MMI}}\right)= & \exp \left(j(2 q+1) \frac{\pi}{3}\right)\left[\sum_{\nu \text { even }} c_{\nu} h_{x, \nu}(y)\right. \\
& \left.+\sum_{\nu \text { odd }} c_{\nu} h_{x, \nu}(y) \exp (j(2 q+1) \pi)\right] .
\end{aligned}
$$

Dropping the overall phase factor, this turns out to be

$$
h_{x}\left(y, L_{\mathrm{MMI}}\right)=\sum_{\nu}(-1)^{\nu+1} c_{\nu} h_{x, \nu}(y) .
$$

The field at the end of the MMI section is an $x z$-plane mirror image of the field at the entrance, which means that the coupler is in the cross state. For $L_{\mathrm{MMI}}=(q+1 / 2) L_{\pi}$, substitution into (A2) sheds:

$$
\begin{aligned}
h_{x}\left(y, L_{\mathrm{MMI}}\right)=\sum_{p=0}^{S}[ & c_{3 p} h_{x, 3 p}(y) \exp \left(j(2 q+1) \pi \frac{(3 p+1)^{2}}{6}\right) \\
& +c_{3 p+1} h_{x, 3 p+1}(y) \\
& \left.\cdot \exp \left(j(2 q+1) \pi \frac{(3 p+2)^{2}}{6}\right)\right] \quad \text { (A13) }
\end{aligned}
$$

which, taking into account (A7) and (A8) can be developed into

$$
\begin{aligned}
h_{x}\left(y, L_{\mathrm{MMI}}\right)=\sum_{p \text { even }}\left[c_{3 p} h_{x, 3 p}(y) \exp \left(j(2 q+1) \frac{\pi}{6}\right)\right. \\
+c_{3 p+1} h_{x, 3 p+1}(y) \\
\left.\cdot \exp \left(j(2 q+1) \frac{4 \pi}{6}\right)\right] \\
+\sum_{p \text { odd }}\left[c_{3 p} h_{x, 3 p}(y) \exp \left(j(2 q+1) \frac{4 \pi}{6}\right)\right. \\
+c_{3 p+1} h_{x, 3 p+1}(y) \\
\left.\cdot \exp \left(j(2 q+1) \frac{\pi}{6}\right)\right] .
\end{aligned}
$$

With the same considerations as before, we return to the $\nu$ index

$h_{x}\left(y, L_{\mathrm{MMI}}\right)=\sum_{\nu \text { even }} c_{\nu} h_{x, \nu}(y) \exp \left(j(2 q+1) \frac{\pi}{6}\right)$ 


$$
\begin{aligned}
&+ \sum_{\nu \text { odd }} c_{\nu} h_{x, \nu}(y) \\
& \cdot \exp \left(j(2 q+1) \frac{4 \pi}{6}\right) \\
& h_{x}\left(y, L_{\text {XMI }}\right)= \exp \left(j(2 q+1) \frac{\pi}{6}\right) \\
& \cdot {\left[\sum_{\nu \text { even }} c_{\nu} h_{x, \nu}(y)+\sum_{\nu \text { odd }} c_{\nu} h_{x, \nu}(y)\right.} \\
&\left.\cdot \exp \left(j(2 q+1) \frac{\pi}{2}\right)\right] .
\end{aligned}
$$

Dropping the overall phase factor, this turns out to be

$$
h_{x}\left(y, L_{\mathrm{MMI}}\right)=\sum_{\nu \text { even }} c_{\nu} h_{x, \nu}(y)+\sum_{\nu \text { odd }}(-1)^{q} c_{\nu} h_{x, \nu}(y) .
$$

The field at the end of the MMI section is a linear combination of the even and odd modes with a relative phase of $\pi / 2$, which means that the coupler operates in the $3-\mathrm{dB}$ state.

\section{ACKNOWLEDGMENT}

The authors wish to thank J. W. M. van Uffelen and A. H. de Vreede for making the devices and providing useful technical advice, and Philips Research Laboratories in Eindhoven for polishing the samples.

\section{REFERENCES}

[1] M. Papuchon, A. Roy, and D. B. Ostrowsky, "Electrically active optical bifurcation: BOA," Appl. Phys. Lett., vol. 31, no. 4, pp. 266-267, 1977.

[2] F. Rottmann, A. Neyer, W. Mevenkamp, and E. Voges, "Integratedoptic wavelength multiplexers on Lithium Niobate based on two-mode interference," J. Lightwave Technol., vol. 6, pp. 946-952, 1988

[3] C. Caldera et al., "3-dB couplers integrated in InGaAlAs/InP for coherent applications," in Proc. ECOC' 90 (Amsterdam), 1990, pp. 357-360.

[4] S. Gevorgyan and A. Hovsepyan, "Coupling among waveguides of small spacing" Electron Lett, vol. 24 no 1, pp $814-815,1988$.

[5] L. B. Soldano, F. B. Veerman, M. K. Smit, B. H. Verbeek, and E. C. M. Pennings, "Multimode Interference couplers," Proc. IPR Top. Meet. paper TuD1, 1991, p. 13.

[6] E.C.M. Pennings et al., "Ultra-compact, low-loss directional coupler structures on InP for monolithic integration," in Proc. ECOC/IOOC '91, paper WeA7-3, pp. 405-408, 1991.

[7] L. B. Soldano et al., "High-performance monomode planar couplers using a short multi-mode interference section," in Proc, ECOC/IOOC'91, paper TuB5-2, pp. 225-228, 1991.

[8] O. Bryngdahl, "Image formation using self-imaging techniques," J. Opt. Soc. Amer., vol. 63 , no. 4 , pp. $416-418,1973$.

[9] R. Ulrich and G. Ankele, "Self-imaging in homogeneous planar optical waveguides," Appl. Phys. Lett., vol. 27, no. 6, pp. 337-339, 1975.

[10] R. Ulrich and T. Kamiya, "Resolution of self-images in planar optica waveguides," J. Opt. Soc. Amer., vol. 68, no. 5, pp. 583-592, 1978

[11] R. M. Knox and P.P. Toulios, "Integrated circuits for the millimeter through optical frequency region," in Proc. MRI Symp. Submillimiter Waves, pp. 497-516, 1970.

[12] M. K. Smit, "Integrated optics in silicon-based aluminum oxide," Ph.D. Thesis, Delft University of Technology, 1991

[13] W. A. Pasmooij, P. A. Mandersloot, and M. K. Smit, "Prism-coupling of light into narrow planar optical waveguides," J. Lightwave Technol., vol. 7, pp. $175-180,1989$.

[14] L. B. Soldano et al., "New all-passive $4 \times 4$ planar optical phase diversity network," in Proc. ECOC/IOOC '91, paper C.PDP.1, pp. 96-99, 1991.

[15] J. E. Zucker, K. L. Jones, T. H. Chiu, B. Tell, and K. Brown-Goebeler, "Polarization-independent electro-optic waveguide switch using strained InGaAs/Inp quantum wells," Proc. IPR'92, 1992, paper Pd 7, pp. 21-24.

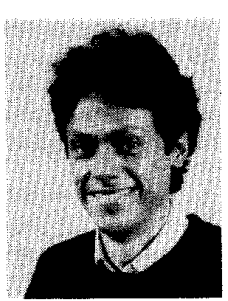

Lucas B. Soldano was born in Buenos Aires, Argentina, on June 1, 1960. He studied at Buenos Aires University, where he obtained a degree in electronics engineering in 1988. During his studies he was active in the field of gas and solid-state lasers. In 1991 he was awarded a Design Engineer degree in Microelectronics, by the Delft University of Technology, Delft, The Netherlands. He is currently working toward the Ph.D. degree at the Delft University of Technology. His present research work deals with integrated optical components for telecommunications.

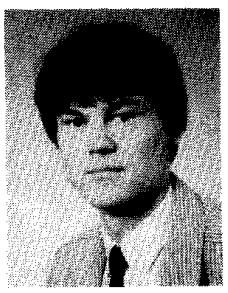

Frank B. Veerman was born in Eindhoven, the Netherlands, on September 14, 1966. He graduated in 1990 in electrical engineering at Delft University of Technology, Delft, the Netherlands.

$\mathrm{He}$ is currently working at the NMB Postbank Group N.V. as a network engineer.

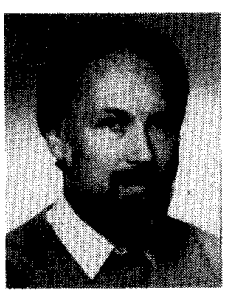

Meint K. Smit was born in Vlissingen, the Netherlands, on January 5, 1951. He graduated in 1974 in electrical engineering at the Delft University of Technology, Delft, the Netherlands, and received the $\mathrm{Ph} . \mathrm{D}$. degree in 1991.

From 1974 to 1981 he worked in the field of radar remote sensing, as a research assistant to the NIWARS and since 1976 as a staff member of the Delft University. From 1981 he has worked in the field of integrated optics with emphasis on passive optical components on silicon substrates for use in optical communication. Since 1986 he is also engaged in research on the realization of integrated optical circuits in the InGaAsP/InP system.
Bastiaan H. Verbeek received the M.S. degree in 1975 and the Ph.D. degree (cum laude) in 1979.

Subsequently he joined the Philips Research Labs in Eindhoven, the Netherlands, where he has been engaged with the electronic structure of metalsemiconductor compounds and later with physies of $\mathrm{AlGaAs}$ semiconductor lasers for CD-applications. In 1986 he worked as a visiting research scientist at AT\&T Bell Labs., Murray Hill, NJ on semiconductor lasers and integrated optics for telecommunications applications. He retumed to Philips Research in 1987, where his main areas of research in the Philips Optoelectronic Centre are lasers, optical amplifiers and InP based integrated optics for coherent communication systems, also in European RACE projects. He is also a part-time professor at the Technical University of Delft giving lectures on optical fiber communication technology and integrated optics and leads the Integrated Optic research group. He is author and co-author of over 40 scientific publications and presented conference papers. 


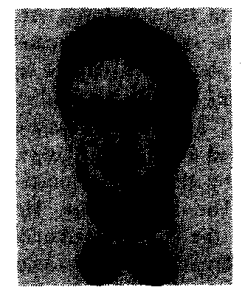

Alain H. Dubost was born in Lyon, France, on August 25, 1968. He graduated in electrical engineering and communications from the Ecole $\mathrm{Na}$ tionale Supérieure des Télécommunications, Paris,

France, in 1991. During his study he was engaged in integrated optics research.

$\mathrm{He}$ is currently working at the Nuclear Research Centre at Vaujours, France, where he is involved in both the optimization of streak camera measurements and the characterization of optical probes.

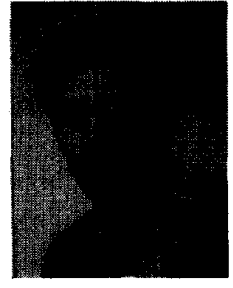

Erik C. M. Pennings (S'88-M'90) was born in Sassenheim, the Netherlands, on November 3, 1960. He received the M.Sc. degree (cum laude) in physics from Groningen University, the Netherlands, in 1986 and the Ph.D. degree in electrical engineering from Delft University of Technology, Delft, the Netherlands, in 1990. His dissertation deals with the modeling of and experiments on bends in optical ridge waveguides. Subsequently, he joined Bell Communications Research as a postdoctoral member of technical staff. His main interests are in integrated optoelectronics.

Dr. Pennings is a member of the OSA and the SPIE. 